\title{
Treatment of the Open Abdomen with the Commercially Available Vacuum-Assisted Closure System in Patients with Abdominal Sepsis
}

\author{
U. Zingg - A. Platz
}

Published online: 4 March 2009

(c) Société Internationale de Chirurgie 2009

We thank Dr. Perathoner and colleagues for their interest in our article [1]. The median time interval between the first surgery and the application of the vacuum-assisted closure (VAC) system was 7 (range, 0-17) days. In three patients, the VAC system was applied at time of the primary operation, in 14 patients at time of the first revision (median, 5 days after the primary surgery; range, 1-12 days), and in 13 patients at time of the second revision (median, 11 days after primary surgery; range, 5-17 days). The primary outcome of our study was closure of the fascia, and we did not evaluate or mention the time of use of subcutaneous VAC systems. We are convinced that the crucial steps of treatment are mostly finished when the intra-abdominal sepsis is resolved and the fascia is closed or when an inlay mesh could be implanted. The treatment of the resulting subcutaneous wounds was partially performed in an outpatient setting, and the time intervals would probably not reflect the fastest approach to complete wound closure.

We agree with the observation of Perathoner et al. that the VAC system alone is insufficient to avoid fascial retraction. The concept of dynamic sutures as an adjuvant to avoid fascial retraction is interesting and needs further assessment in randomized trials. The use of additional sutures on the fascial edges may have the disadvantage of further reducing the quality of the fascia, especially in patients who need multiple revisions. Therefore, in our view, the most important factor to ensure primary closure is early, stepwise closure of the fascia.

The VAC system has improved the treatment of patients with abdominal sepsis and provides a safe treatment option with low system-related morbidity. However, as Perathoner and colleagues mentioned, there is a need for further trials with larger cohort numbers and clear definitions on abdominal sepsis to evaluate the optimal use of the VAC system in these critically ill patients.

\section{References}

1. Wondberg D, Larusson HJ, Metzger U et al (2008) Treatment of the open abdomen with the commercially available vacuumassisted closure system in patients with abdominal sepsis: low primary closure rate. World J Surg 32:2724-2729
U. Zingg · A. Platz

Department of Surgery, Triemli Hospital Zurich, Zurich 8063,

Switzerland

\section{U. Zingg ( $\square)$}

Department of Surgery, University Hospital Basel,

Spitalstrasse 21, 4031 Basel, Switzerland

e-mail: uzingg@uhbs.ch

\section{U. Zingg}

Flinders University Department of Surgery, Flinders Medical

Centre, Bedford Park, Adelaide 5042, SA, Australia 